\title{
Environmental tobacco smoke
}

\section{P R Edwards, M van Tongeren, A Watson, I Gee, R E Edwards}

\section{UK workplace regulations leave hospitality trade workforce unprotected}

B ans on smoking in public places and workplaces, including bars and restaurants, have recently been introduced in California and New York City and have been announced in Ireland. In addition, the UK Chief Medical Officer ${ }^{1}$ and the EU Health Commissioner have recently called for a ban on smoking in public places. Despite clear evidence that environmental tobacco smoke (ETS) adversely affects health and is an important occupational health hazard, the current UK policy response and regulatory framework for occupational ETS exposure remains inadequate with no discernable scientific rationale.

ETS is a complex mixture of over 3800 gaseous and particulate components, including more than 50 known or suspected human carcinogens and 100 toxic chemicals. Exposure to ETS through passive smoking has been associated with many diseases including lung cancer, and cardiovascular and respiratory diseases. ${ }^{2}{ }^{3}$ The impact on cardiovascular disease is particularly important from an occupational and public health perspective. Steenland et al recently estimated that in the USA there are 2000-3000 deaths annually among non-smokers from cardiovascular related disease due to occupational exposure to ETS. ${ }^{4}$

Occupational exposure to ETS is widespread, with an estimated 7.5 million workers in the EU and 1.3 million workers in the UK exposed to ETS for at least $75 \%$ of their working time. ${ }^{5}$ Many are employed in the hospitality industry on a casual basis in bars, pubs, restaurants, hotels, and nightclubs. Studies have shown high ETS marker concentrations levels in a range of hospitality settings. ${ }^{67}$

\section{"Control measures should be imple- mented to reduce occupational exposure"}

The UK has no specific regulatory framework for occupational ETS exposure. The Health and Safety at Work Act (1974) requires employers "to provide and maintain a safe working environpracticable, safe, without risks to health ...". Each year, The Health and Safety Commission (HSC) publishes occupational exposure standards (OESs) and maximum exposure limits (MELs) for pollutants. ${ }^{8}$ The Control of Substances Hazardous to Health (COSHH) Regulations, $2002^{9}$ state that employers should prevent exposure of their employees to substances hazardous to health or, where this is not reasonably practicable, ensure that exposures are adequately controlled. If substances cannot be eliminated, then control measures should be implemented to reduce occupational exposure, for example by enclosure of the source, localised ventilation, or as a last resort, by using respiratory protection. However, there is no occupational exposure standard for ETS, although many constituents of ETS have OESs or MELs (for example, benzene). The recent classification of involuntary tobacco smoke exposure as a class I carcinogen by the International Agency for Research in Cancer (IARC), ${ }^{10}$ should increase pressure on the HSC to set a standard for ETS.

In 1998, the UK Government announced in the white paper "Smoking kills" that it would consult about the introduction of an Approved Code of Practice (ACoP) on workplace passive smoking. ${ }^{11}$ The ACoP consultation document ${ }^{12}$ set out a hierarchy of measures with the preferred option being a complete ban on smoking "where it was reasonable and practical" to do so. Other possibilities included physical separation of smoking and non-smoking employees, and not restricting smoking but "adequately" ventilating the workplace. The HSC recommended immediate implementation of the ACoP in October 2000, arguing that it would have significant health benefits, but the government has taken no action to do so.

The other main component of the UK Government's policy on passive smoking is the Public Places Charter, ${ }^{11}$ which is a voluntary, self-regulatory, charter supported by the main hospitality industry organisations. Compliance with this charter includes provision of ment which is so far as reasonably no-smoking areas with or without mechanical ventilation, and even allowing smoking throughout the premises, provided that this is clearly indicated using visible signs and supported by a written smoking policy. The latter option was adopted by $49 \%$ of Charter compliant pubs in 2003. The Charter does not address (nor was it designed to address) occupational exposure to passive smoking. This voluntary Charter is monitored and promoted in the hospitality industry by Atmosphere Improves Results (AIR), ${ }^{13}$ which is a lobby group funded by the Tobacco Manufacturers Association.

"The level of ETS exposure at which risk becomes acceptable is undefined"

The Public Places Charter and the draft ACoP both promote ventilation as a method for addressing ETS exposure in public places and workplaces. However, the benefits are described with reference to improved comfort rather than reduction in risk. There is little research on the effectiveness of general ventilation in removing ETS or in estimating associated reductions in risk. Indeed, the level of ETS exposure at which risk becomes acceptable is undefined. A recent UK study ${ }^{14}$ found that the concentrations of a range of ETS markers, though still high, were significantly lower $(p<0.05)$ in non-smoking compared to smoking areas of pubs. However, ventilation systems (sophisticated HVAC systems and extractor fans in either the on or off mode) did not significantly reduce ETS marker concentrations in either smoking or nonsmoking areas. This suggests that existing ventilation systems may be ineffective in reducing ETS exposure and hence have little effect in reducing health risk for staff and public in hospitality environments

The ventilation systems currently used in pubs and bars have generally not been installed to control ETS exposure of employees but rather to improve physical comfort for customers. Alternative ventilation approaches may be effective but these will require objective assessment before the industry's claims for ventilation solutions can be accepted. An essential requirement for assessing ventilation solutions will be the development of a consensus ETS guideline or standard value that the ventilation system must achieve, as called for in the ASHRAE 62 ventilation standard for acceptable air quality. ${ }^{15}$

On current evidence, the only measure guaranteed to protect employees from health risks associated with occupational ETS exposure is removal of the 
source of exposure-that is, by providing smoke free hospitality environments. Support for this approach comes from a study in San Francisco which showed that the introduction of smoke-free bars was associated with a rapid improvement of respiratory health among bartenders. ${ }^{16}$

\section{"Smoke-free policies do not have a negative impact on revenue or jobs"}

The main objection raised to providing smoke-free environments in the hospitality industry is that it will result in ruinous economic consequences due to loss of revenue from smoking customers. This is not supported by evidence. A recent systematic review found that of 21 well designed studies on the impact of smoke-free policies in the hospitality trade, none showed a negative impact on revenue or jobs. ${ }^{17}$ Furthermore, there is clear evidence of public support in the UK for restrictions on smoking in the workplace and public places. ${ }^{18}$

It is clear that for informed policy decisions about involuntary occupational ETS exposure to be made, a health based review of safe exposure levels for workers and the public, and subsequent development of health based exposure limits is urgently required. More research is needed to determine whether sophisticated ventilation systems or other available engineering solutions are effective in reducing exposure to ETS and minimising adverse heath effects.

Until there is clear evidence that ventilation systems can reduce personal ETS exposures of employees to a level at which there is no significant health risk, the most rational regulatory solution is to require that workplaces are smoke-free, including in the hospitality sector. In the absence of effective ventilation control measures and the continued (but disputed) argument made by the hospitality industry that banning smoking is not reasonably practicable on economic grounds, the remaining alternative according to the COSHH hierarchy of control measures would be to provide and enforce the use of personal protective equipment, a measure that would probably be unacceptable to staff, customers, and the industry. If, despite increasing scientific evidence about the dangers of occupational exposure to ETS, the hospitality industry does not act and is hence is not seen to exercise its duty of care towards its employees, it is potentially opening itself up to future, costly litigation. Does the hospitality industry really want to take that risk?

Occup Environ Med 2004;61:385-386. doi: 10.1136/oem.2003.011692

\section{Authors' affiliations}

P R Edwards, Evidence for Population Health Unit, School of Epidemiology and Health

Sciences, University of Manchester, UK

$M$ van Tongeren, Centre for Occupational and Environmental Health, School of Epidemiology and Health Sciences, University of Manchester, UK

A Watson, I Gee, ARIC, Department of Environmental \& Geographical Sciences, Manchester Metropolitan University, UK

R E Edwards, The Manchester Centre for Civil and Construction Engineering, UMIST, Manchester, UK

Correspondence to: Dr P Richard Edwards, Evidence for Population Health Unit, School of Epidemiology and Health Sciences, Stopford University of Manchester, Stopford Building, Oxford Rd, Manchester MP13 9PT, UK; richard.edwards@man.ac.uk

Competing interests: Richard Edwards is unpaid Chair of North West Action on Smoking and Health and a member of the Royal College of Physicians Tobacco Control Group

\section{REFERENCES}

1 Donaldson L. Health check on the state of the public health: the annual report of the Chief Medical Officer 2002. London: Department of Health, 2003.
2 Scientific Committee on Tobacco and Health Report of the Scientific Committee on Tobacco and Health. London: The Stationery Office, 1998.

3 WHO Regional Office for Europe. Environmental tobacco smoke. World Health Organisation, 2000

4 Steenland K, Burnett C, Lalich N, et al. Dying for work: the magnitude of US mortality from selected causes of death associated with occupation. Am J Ind Med 2003;43:461-82.

5 Kauppinen T, Toikkanen J, Pedersen D, et al. Occupational exposure to carcinogens in the European Union. Occup Environ Med 2000;57:10-18.

6 Jarvis M. Quantitative survey of exposures to other people's smoke in London bar staff. London: Department of Epidemiology and Public Health, University College London, 2001.

7 Siegel M. Involuntary smoking in the restaurant workplace. A review of employee exposure and health effects. JAMA 1993;270:490-3.

8 Health and Safety Executive. EH40/2002. Occupational exposure limits 2002. London: HSE Books, 2002.

9 Health and Safety Executive. Control of substances hazardous to health regulations 2002 Approved code of practice and guidance. $L 5$. London: HSE Books, 2002.

10 International Agency on Research on Cancer. Tobacco smoke and involuntary smoking (June 2002). http://monographs.iarc.fr/htdocs/ monographs/vol83/02-involuntary.html (accessed 29 August 2003). IARC Monographs (Vol. 83). Lyon: International Agency on Research on Cancer, Lyon, 2003.

11 Secretary of State for Health. Smoking kills: a White Paper on tobacco. London: The Stationery Office, 1998.

12 Health and Safety Commission. Proposal for an Approved Code of Practice on passive smoking at work: consultative document. London: Health and Safety Executive, 1999

13 Atmosphere Improves Results. Atmosphere Improves Results. http://www.airinitiative.com/ (accessed 29 October 2003). London: Atmosphere Improves Results, 2003.

14 Carrington J, Watson AFR, Gee IL. The effects of smoking status and ventilation on environmental tobacco smoke concentrations in public areas of UK pubs and bars. Atmospheric Environment 2003;37:3255-66.

15 ASHRAE. Addendum 62 to ASHRAE Standard 62-2001: Ventilation for Acceptable Air Quality 2002. Atlanta: American Society of Heating, Refrigerating and Air-Conditioning Engineers, 2002.

16 Eisner MD, Smith AK, Blanc PD. Bartenders' respiratory health after establishment of smokefree bars and taverns. JAMA 1998;280:1909-14.

17 Scollo M, Lal A, Hyland A, et al. Review of the quality of studies on the economic effects of smoke-free policies on the hospitality industry. Tobacco Control 2003;12:13-20.

18 Office for National Statistics. Smoking related behaviour and attitudes 2002. London: The Stationery Office, 2003. 